\title{
PUFAs from Stem Bark of Alstonia boonei Synergistically Modulates Diabetic, Hepatic and Androgenic Damage by Low Expression of COX-2 and iNOS in Rats
}

\author{
Ajiboye $\mathrm{JA}^{1^{*}}$, Akintunde $\mathrm{JK}^{2}$, Okewuyi $\mathrm{SO}^{3}$ and Okafor UE ${ }^{1}$ \\ ${ }^{1}$ Department of Chemical Sciences, Biochemistry unit, College of Natural and Applied Sciences, Bells University of Technology Ota, Ogun State Nigeria \\ ${ }^{2}$ Toxicology and Safety Unit, Department of Environmental Health Sciences, Faculty of Public Health, College of Medicine, University of Ibadan, Nigeria \\ ${ }^{3}$ Drug Metabolism and Molecular Toxicology Research Laboratories, Department of Biochemistry, College of Medicine, University of Ibadan, Nigeria
}

Corresponding author: Ajiboye JA, Department of Chemical Sciences, Biochemistry unit, College of Natural and Applied Sciences, Bells University of Technology Ota, Ogun State Nigeria, Tel: +234 818444 2354; Fax: +23408064156056; E-mail: akintundejacob@yahoo.com

Rec Date: Nov 09, 2016, Acc Date: Dec 28, 2016, Pub Date: Dec 30, 2016

Copyright: ( 2016 Ajiboye JA, et al. This is an open-access article distributed under the terms of the Creative Commons Attribution License, which permits unrestricted use, distribution, and reproduction in any medium, provided the original author and source are credited.

\begin{abstract}
PUFAs, from the stem bark extract of Alstonia boonei (SBEAB) was hypothesized to possess anti-inflammatory, antioxidant, anti-diabetic, pro-spermatogenic and hepatoprotective activities. The present study investigated the possible biochemical and molecular mechanisms underlying the hepatoprotective and testoprotective effects of SBEAB in diabetic rat. Biomarkers of hepatic and testicular damage, histological and immunohistochemical techniques were used. The expression of cyclooxygenase (COX-2) and inducible nitric oxide synthase (iNOS) were also estimated. SBEAB administered orally at dose of $100 \mathrm{mg} / \mathrm{kg}$ for 14 days significantly lowered the activities of serum transaminases and MDA levels induced by single intraperitoneal administration of streptozotoxin (STREP) $(80 \mathrm{mg} / \mathrm{kg})$ and preserved the integrity of both hepatocytes and spermatocytes. Also, SBEAB elevated the STREPinduced reduced activities of $\triangle 5-17 \beta-H S D$ and $\triangle 5-17 \beta-H S D$ with corresponding decrease in the activity of CAT. SBEAB inhibited the STREP induced expression of COX-2 and iNOS. The protective effect of SBEAB was compared to that of metaglomide (METAG), an established anti-diabetic drug. METAG treatment on hepatic damage was most efficacious in diabetic rats; followed by post and pre-treatment respectively while pre-and post-treatment were more efficacious on testicular damage than anti-diabetic drug. Furthermore, pre and post-treatment were more efficacious in preventing pro-inflammation and testicular cancer in diabetic rats than METAG-administration. We therefore concluded that the repression of genes encoding COX-2 and iNOS proteins by SBEAB validates the molecular basis of testicular protection and further suggests the links between the hepatocellular damage and male reproductive dysfunctions in diabetic individuals.
\end{abstract}

Keywords: SBEAB; PUFAs; Pro-inflammation; Synergy; Diabetic rats

\section{Introduction}

Diabetes mellitus (DM) is one of the well-known public health risks in contemporary societies and its occurrence is geometrically increasing. A recent report speculated that before 2030, diabetes would have affected approximately $40 \%$ increase of the world population [1]. Also, male reproductive challenges of modern societies reveal that the increased incidence of DM was closely linked with falling birth rates and infertility $[2,3]$. This could be attributed to the disturbing increase of diabetic men in reproductive age. Previous work reported that patients with type 1 diabetes (T1D) were identified before the age of 30 [4] and that the number of young persons with T1D and type 2 diabetes (T2D) were uncontrollably high [5]. Further investigations also reported that sexual disorders, such as erectile dysfunction [6] or retrograde ejaculation [7], were manifested in diabetic individuals and generally resulted in a reduced libido [8]. Although, the decline in reproductive health of male diabetics can be attenuated in patients but the molecular mechanism of metabolic pathways aside glucose transport to the cells, remain undisclosed and obscure $[9,10]$. Essentially, the links between male reproductive dysfunctions and hepatic damage in diabetic induced rats are scarcely elucidated.
Cyclooxygenase-2 (COX-2) and inducible nitric oxide synthase (iNOS) can be induced quickly by pro-inflammatory mediators, endotoxins and carcinogens [11]. Some recent studies have demonstrated that carcinogens were capable of provoking COX-2 expression via activation of transcription factors $[12,13]$. However, targeted inhibitions of COX-2 and iNOS were recently recognized as the molecular basis for cancer prevention [13]. Also, health-promoting plants origin are linked to the presence of essential phenolic phytochemicals including phenolic acids, PUFAs and flavonoids [14-16]. Phenolic compounds are secondary metabolites of plants which exhibit strong antioxidant activity and play crucial role in health promotion and disease aversion [17].

The herbs produced from stem barks have been used as healing mediators and as anti-hepatic damage for thousands of years [18]. Herbs have also been recognized to possess medicinal properties [19]. The herbal therapies with high phenolic content are preponderant in the West Africa especially the tropical Africa [20,21]. They are administered with a drink to treat colds and several assaults $[18,20]$. The present stem bark of this study belongs to the family of apocynaceae (Alstonia boonei); also, known as God's tree. It is employed as an alternative medicine for many complicated ailments and used for medicinal purposes such as antirheumatic [22], painreliever, antipyretic, antimicrobial, and antibiotic properties [23]. Recent findings reported the hypoglycaemic properties of stem bark 
Citation: Ajiboye JA, Akintunde JK, Okewuyi SO, Okafor UE (2017) PUFAs from Stem Bark of Alstonia boonei Synergistically Modulates Diabetic, Hepatic and Androgenic Damage by Low Expression of COX-2 and iNOS in Rats. J Mol Biomark Diagn 8: 334.

extract Alstonia boonei (SBEAB) in diabetic albino rats. In addition, the stems of the plant have been shown to possess anti-inflammatory properties and potential therapeutic effect on reproductive dysfunctions and cardiovascular diseases [22]. Apocynaceae is useful in herbal medicine against diabetes and considered as safe herbal medicine because no significant side effect had been discovered [22] For this reason, considering the beneficial actions of the stem bark and its use in the traditional medicine as therapy against diabetes as well as its anti-inflammatory importance for reproductive functioning, the aim of the present study was to evaluate the effect of combined PUFAs from stem bark of Alstonia boonei (SBEAB) on activity of enzymes linked to testicular pro-inflammation, liver and androgenic damage in streptozotocin (STREP) -induced diabetic rats.

\section{Materials and Methods}

\section{Sample selection}

Fresh sample of stem bark of Alstonia boonei was purchased from the local market, in Ota metropolis, Ogun State, Nigeria. Authentication of the plant was carried out in the Department of Biology, University of Ibadan, Nigeria. Adult male wistar strain albino rat was purchased from the Biochemistry Department animal colony, University of Ibadan, Nigeria and maintained ad libitum on commercial diet and water.

\section{Chemicals and reagents}

STREP was purchased from Sigma Chemical Co. (St Louis, MO, USA). Rabbit polyclonal COX-2 and iNOS antibodies were products of Cayman Chemical Co. (Ann Arbor, MI, USA). Bovine Serum Albumin (BSA), hydrogen peroxide, trichloroacetic acid (TCA) and thiobarbituric acid (TBA) were purchased from Sigma (St Louis, MO, USA). All the kits used for the bioassay were sourced from Randox Laboratories Ltd. (Crumlin, Dublin, Northern Ireland, UK). All other reagents used were in the purest form available commercially.

\section{Extraction of stem bark Alstonia boonei}

The bark of the stem was thoroughly washed in distilled water to remove any contaminant, chopped into small pieces before being milled. The ethanol extract of the stem was subsequently prepared by soaking the grinded sample $(10 \mathrm{~g})$ in ethanol $(200 \mathrm{ml})$ for about $24 \mathrm{~h}$ at $37^{\circ} \mathrm{C}$; the mixture was filtered and the filtrate was concentrated by rotator evaporator designated as SBEAB and stored in the refrigerator for subsequent analysis.

\section{Gas Chromatography - Mass Spectrum Analysis (GC-MS)}

The crude extract was subjected to column chromatography over silica-gel (100-200 mesh) and eluted with ethanol. The ethanol fraction of stem bark of Alstonia boonei was taken for GC-MS analysis. GC-MS analysis was carried out on a GC Clarus 500 Perlin Elma system comprising a AOC-20i auto-sampler and gas chromatography interfaced to a mass spectrophotometer (GC-MS) instrument employing the following conditions: column Elite- 1 fused silica capillary column $(30 \times 0.25 \mathrm{~mm} \times$ ID $1 \mathrm{EM}$ df, composed of $100 \%$ Dimethyl polysiloxane), operating in electron impact mode at $70 \mathrm{eV}$; helium (99.999\%) was used as a carrier gas at a constant flow of 1 $\mathrm{ml} / \mathrm{min}$ and an injection of volume of $0.5 \mathrm{EI}$ was employed (split ratio of $10: 1$ injector temperature $250^{\circ} \mathrm{C}$ ); ion-source temperature $280^{\circ} \mathrm{C}$. The oven temperature was programmed from $110^{\circ} \mathrm{C}$ (isothermal for 2 min) with an increase of $10^{\circ} \mathrm{C} / \mathrm{min}$, to $200^{\circ} \mathrm{C}$ then $5^{\circ} \mathrm{C} / \mathrm{min}$ to $280^{\circ} \mathrm{C}$, ending with a $9^{\circ} \mathrm{C} / \mathrm{min}$ isothermal at $280^{\circ} \mathrm{C}$. Mass spectra were taken at $70 \mathrm{eV}$; a scan interval of $0.5 \mathrm{~s}$ and fragments from 40 to $550 \mathrm{Da}$.

\section{Identification of components}

Interpretation on mass spectrum GC-MS was conducted using database of National Institute Standard and Technology (NIST) having more than 62,000 patterns. The spectrum of the unknown components was compared with the spectrum of the known components stored in the NIST library. The molecular name and their percentage composition of the components of the test materials were ascertained.

\section{Animal treatment}

Adult male Wistar rats (200-300 g) from the Central Animal House of the Bells' University of Technology, Ota, Nigeria were used in this experiment. The animals were maintained at a constant temperature $\left(22 \pm 2^{\circ} \mathrm{C}\right)$ on a $12 \mathrm{~h} \mathrm{light/dark} \mathrm{cycle} \mathrm{with} \mathrm{free} \mathrm{access} \mathrm{to} \mathrm{food} \mathrm{and} \mathrm{water.}$ Animal care and handling was done according to the institutional guidelines of Nigeria Academy. The study was approved by the Institutional Animal Ethical Committee.

\section{Experimental protocol}

The rats were acclimatized for two weeks and randomly divided into five groups of eight animals each $(n=8)$. Group 1 (Control): serve as the normodiabetic control group; Group 2 (Induced): serve as the diabetics group induced with STREP plus nicotinamide adenine dinucleotide (NAD) (STREP+ NAD); Group 3 serve as the positive control induced with STREP plus metaglomide (METAG) plus NAD (STREP + METAG + NAD); Group 4 (Pre-treatment): serve as diabetic group pre-treated with $200 \mathrm{mg} / \mathrm{kg}$ body weight of stem bark Alstonia boonei extract (SBEAB before+ NAD + STREP after) [24]; Group 5 (Post-treatment): serve as diabetic group post-treated with $200 \mathrm{mg} / \mathrm{kg}$ body weight of stem bark Alstonia boonei extract(SBEAB after + NAD + STREP before) $120 \mathrm{mg} / \mathrm{kg}$ body weight of nicotinamide (NAD), 80 $\mathrm{mg} / \mathrm{kg}$ body weight of streptozotocin and $5 \mathrm{mg} / \mathrm{kg}$ body weight of metaglomide (METAG) were used. In the normodiabetic groups, the animals received water by gavage throughout the entire experiment to be subjected to the same stress (normodiabetic groups). The experiment lasted for two weeks (14 days).

\section{Diabetic determination}

The animals were subjected to overnight fast prior to the induction of diabetes. Streptozotocin (STREP) freshly prepared in citrate buffer $(0.01 \mathrm{M}, \mathrm{pH} 4.5)$. Rats in groups $2,3,4$ and 5 received a single intraperitoneal dose of STREP $(80 \mathrm{mg} / \mathrm{kg}$ ) for $72 \mathrm{hr}$ [25]. Blood samples were taken by tail vein puncture and glucose levels was monitored using automatic auto-analyzer (Fine test Auto-coding TM). Animals with blood glucose $\geq 200 \mathrm{mg} / \mathrm{dl}$ after $72 \mathrm{~h}$ were considered diabetic and were used in the study. The non-diabetic animal received $1 \mathrm{ml}$ of $0.1 \mathrm{M}$ citrate buffer intraperitoneally. During the experiment, fasting blood glucose was monitored at 3 days interval. The blood was rapidly collected by direct heart puncture and the liver and testes were isolated, rinsed in cold saline $(0.9 \%)$ and homogenized in phosphate buffer ( $\mathrm{pH}$ 7.4). The protective effect of Alstonia boonei on STREPinduced diabetic was compared to that of metaglomide $(5 \mathrm{mg} / \mathrm{kg}$ ) which has been confirmed to have antidiabetic effects [26]. At the end of each experiment, rats were sacrificed by cervical dislocation. Blood was collected by heart puncture for serum isolation. Liver and testes 
Citation: Ajiboye JA, Akintunde JK, Okewuyi SO, Okafor UE (2017) PUFAs from Stem Bark of Alstonia boonei Synergistically Modulates Diabetic, Hepatic and Androgenic Damage by Low Expression of COX-2 and iNOS in Rats. J Mol Biomark Diagn 8: 334.

Page 3 of 9

were excised, rinsed in physiological saline and stored at $4^{\circ} \mathrm{C}$ until use for histopathology and immunohistochemistry.

\section{Measurement of liver enzyme activities}

The activity of Liver enzymes [(Alanine aminotransferase (ALT) and aspartate aminotransferase (AST)] were measured using commercially available kits (Randox Laboratories Kits, St Louis, MO, USA) [27].

\section{Determination of lipid peroxidation and catalase activity}

Lipid peroxidation was assessed in terms of malondialdehyde (MDA) formation in the rat liver 10,000 g supernatant fractions. The measurement of thiobarbituric acid reacting substances (TBARS) was performed as described previously [28]. MDA was quantified and measured as nmole/mg protein. The estimation of catalase [CAT] activity using hydrogen peroxide as substrate was measured according to the method of Clairborne [29]. Protein concentration was determined by the method of Lowry et al. [30].

\section{Histological studies and immunohistochemical staining}

Liver and testes specimen were fixed in $10 \%$ neutral buffered formalin, embedded in paraffin, and sectioned. After deparaffinization and dehydration, the paraffin blocks were stained with hematoxylin and eosin for microscopic examination. For immunohistochemical analysis, the enzymatic activity of endogenous peroxidases in the testes section was first blocked with 3\% hydrogen peroxide, followed by incubation with rabbit polyclonal anti-rat COX-2 and iNOS antibody (Cayman Chemical CO., Ann Arbor, MI, USA) at room temperature for $40 \mathrm{~min}$. The peroxidase binding sites were detected by staining with 3,3-diaminobenzidine tetrahydrochloride (Dako, Glostrup, Denmark). Finally, counterstaining was performed using Mayer's hematoxylin.

\section{Statistical analysis}

The data in each group were expressed as mean \pm standard deviation. A one way analysis of variance (ANOVA) was used to analyze the results and Duncan multiple test was used for the post hoc [31]. Statistical package for Social Science (SPSS) 17.0 for windows was used for the analysis and the least significance difference (LSD) was accepted at $\mathrm{P}<0.05$.

\section{Results}

In other to establish the phyto-active compounds responsible for the biochemical activities of SBEAB, the ethanol extract was quantified for various phytochemicals. As shown in Table 1, GC-MS Chromatogram (peak not shown) provided 22 different poly unsaturated fatty acids (PUFAs). The compound names and their percentage compositions of the unsaturated fatty acids identified in SBEAB were given (Table 1). As observed, GC-MS spectrum showed the predominant presence of 1,2-epoxycyclooctane, trans-2-nonenal, 1-(2-hydroxyl-1-nitroethyl) cyclohexanol and Spiro[1,3-dioxolane-2,2'-6(6,7] diazobicyclo [3.2.2 non-6-ene].

The protective effect of SBEAB on diabetic-induced liver injury was evaluated by determining the levels of AST and ALT. As shown in Table 2, SBEAB pre and post-treatment as well as metaglomide (antidiabetic drug) significantly $(\mathrm{P}<0.05)$ lowered the activities of AST and ALT in diabetic rats which were released into serum as an end point of hepatic damage. In addition, there was a significant decrease in intracellular CAT activity of testes of diabetic-induced rats (Figures 1 and 2) with concomitant increases in MDA production of both liver and testes (Figure 1).

\begin{tabular}{|c|c|}
\hline Phytochemical & $\%$ composition \\
\hline Trans-3-hepten-1-ol & 3.3 \\
\hline 1,2-epoxycyclooctane & $9.0^{*}$ \\
\hline Cyclohexylmethyltrifluoroecetane & 3 \\
\hline Trans-6-nitro-2-hexene & 3 \\
\hline Trans-5-decene & 3.3 \\
\hline Cis-2-nitro-2-hepten-1-ol & 3 \\
\hline Trans-2-nonenal & $11.1^{*}$ \\
\hline 1,2-epoxydodecane & 1.5 \\
\hline 10-undecyn-1-ol & 3.5 \\
\hline 4-chloro-3-hexyltetrahydro-2H-pyran & 1.5 \\
\hline 1-(2-hydroxyl-1-nitroethyl)cyclohexanol & $9.2^{*}$ \\
\hline 13-tetradece-11-yn-1-ol & 3.8 \\
\hline Cis, cis-6,9-pentadecadien-1-ol & 3.5 \\
\hline 2-pentadecyn-1-ol & 1.7 \\
\hline Cis-10-pentadecen-1-ol & 1.5 \\
\hline Palmitic acid & 1.5 \\
\hline Trans,trans, trans- $9,12,15$-octadecatrien-1-ol & 3.8 \\
\hline Oleic acid & 1.7 \\
\hline$\alpha$-linolenic acid & 3.8 \\
\hline n- nonadecanoic acid & 1.5 \\
\hline Octadecanioc acid, 2-(-2hydroxyethoxy) ethyl ester & 1.6 \\
\hline $\begin{array}{l}\text { Spiro[1,3-dioxolane-2,2'-6(6,7]diazobicyclo[3.2.2 non-6- } \\
\text { ene }\end{array}$ & $9.4^{*}$ \\
\hline
\end{tabular}

Table 1: Characterisation of phyto-active components (PUFAs) in ethanol extracts of stem bark Alstonia boonei (SBEAB).

Histological examination of liver samples also agreed with the above observations. Thus, liver specimens from diabetic rats revealed hepatocyte necrosis towards the centrilobular region (Figure $3 \mathrm{~B}$ ) when compared with the control liver (Figure $3 \mathrm{~A}$ ). In metaglomide, SBEAB pre and post-treated rats, the integrity of the hepatocytes was moderately well preserved (Figures 3C-3E). Thus, the defensive effect of metaglomide on hepatic damage was most efficacious in diabetic rats when compared to $\mathrm{SBEAB}$ post and pre-treatment respectively.

\begin{tabular}{|l|l|l|}
\hline Animal Group & ALT & AST \\
$(\mathrm{U} / \mathrm{l})$ & $(\mathrm{U} / \mathrm{l})$ \\
\hline Control & $0.01490 \pm 0.000083 \mathrm{a}$ & $\begin{array}{l}0.02334 \\
0.00025 \mathrm{a}\end{array}$ \\
\hline
\end{tabular}


Citation: Ajiboye JA, Akintunde JK, Okewuyi SO, Okafor UE (2017) PUFAs from Stem Bark of Alstonia boonei Synergistically Modulates Diabetic, Hepatic and Androgenic Damage by Low Expression of COX-2 and iNOS in Rats. J Mol Biomark Diagn 8: 334.

\begin{tabular}{|c|c|c|c|}
\hline Induced & $0.01520 \pm 0.00011 \mathrm{~b}$ & $\begin{array}{l}0.04524 \\
0.00275 b\end{array}$ & \pm \\
\hline Metaglomide & $0.01482 \pm 0.00018 a$ & $\begin{array}{l}0.02332 \\
0.000642 a\end{array}$ & \pm \\
\hline Pretreated & $0.01482 \pm 0.00011 a$ & $\begin{array}{l}0.02366 \\
0.000321 a\end{array}$ & \pm \\
\hline Posttreated & $0.01470 \pm 0.000212 a$ & $\begin{array}{l}0.02488 \\
0.002696 a\end{array}$ & \pm \\
\hline
\end{tabular}

Data are presented as mean $\pm S D(n=8)$. Values with different letters are statistically different.

Table 2: Effect of stem bark extract Alstonia boonei (SBEAB) on the activities of ALT and AST in STREP-induced diabetic rats.
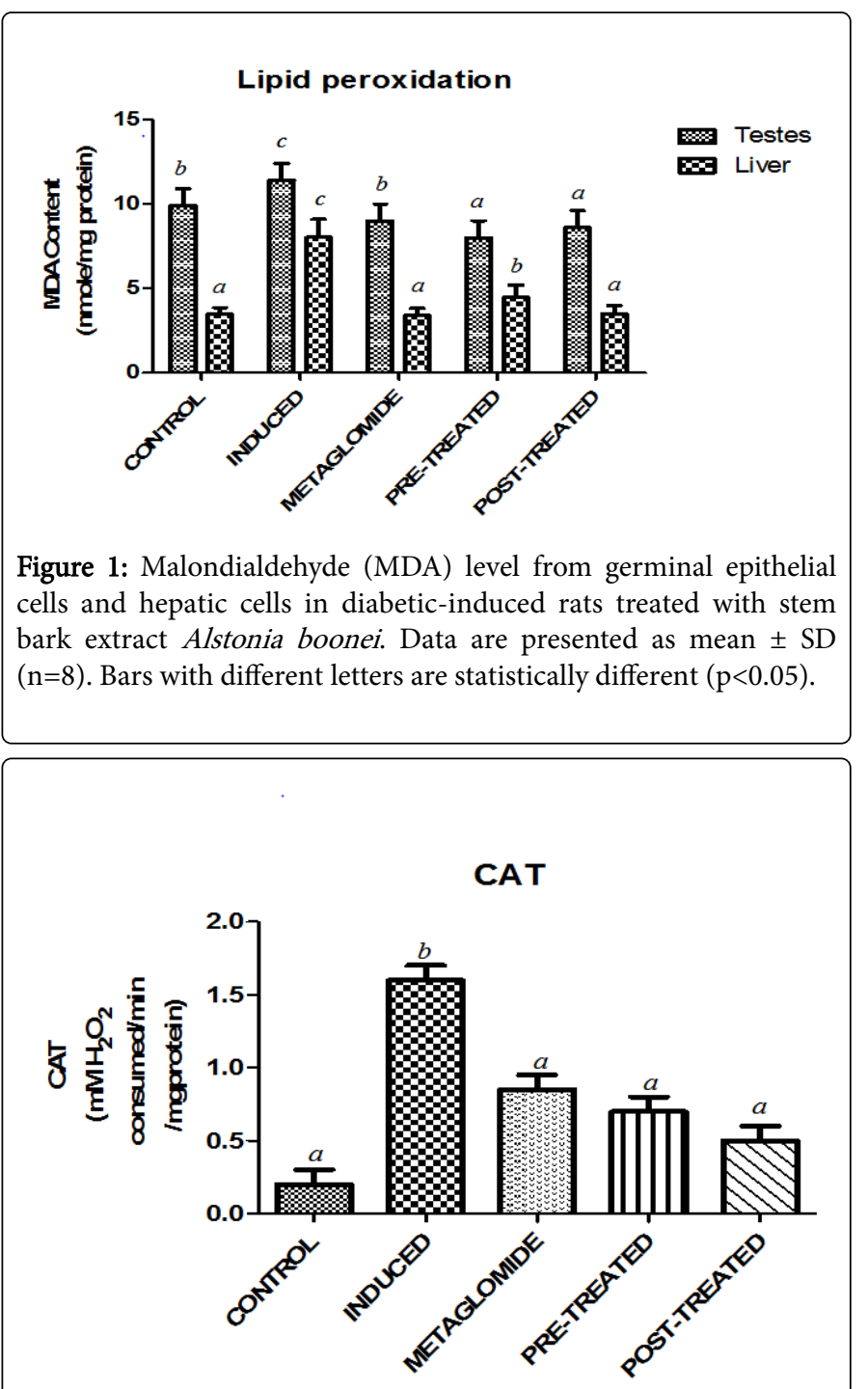

Figure 2: Catalase activity from germinal epithelial cells in diabeticinduced rats treated with stem bark extract Alstonia boonei. Data are presented as mean $\pm S D(n=8)$. Bars with different letters are statistically different.

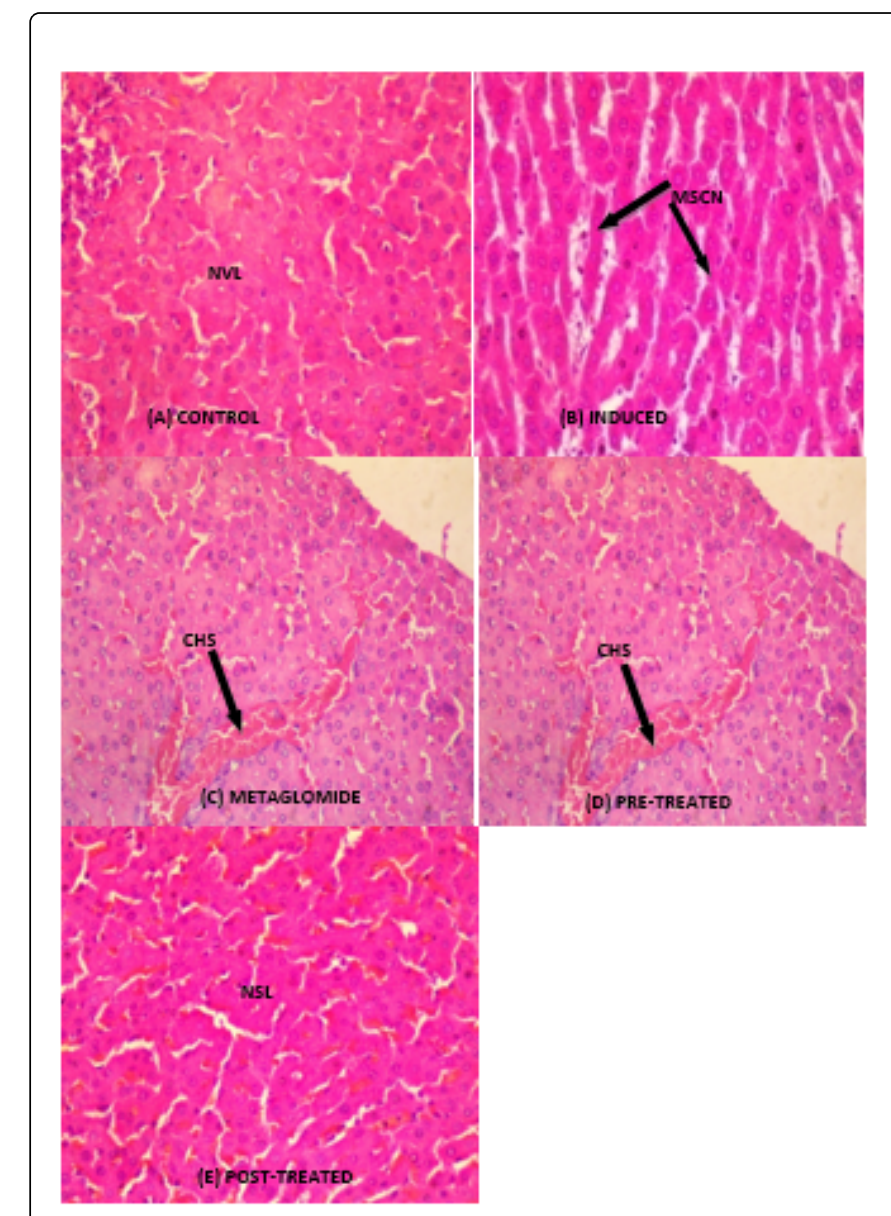

Figure 3: Changes of hepatic histopathology in diabetic rat model (original magnification X 100).

(a) Rats showed no visible lesions to the hepatocytes.

(b) Diabetic rats showed mild single-cell necrosis (MSCN) especially hepatocytes towards left of the centre. Also, closely-packed hepatic cells with a few foci of random necrosis were seen.

(c) Rats treated with metaglomide (anti-diabetic drug) depicted closely packed hepatic cells with moderate congestion of hepatic sinusoids (CHS).

(d) Pre-treated group of animals with the SBEAB demonstrated closely-packed hepatic cells with marked widespread congestion of hepatic sinusoids (CHS). Also, mild Kupffer cell hyperplasia was observed (e) Post-treated group of animals with SBEAB showed closely-packed hepatic cells with no significant lesions (NSL).

The activity of $\Delta 5-3 \beta-H S D$, indicator linked to testosterone production was significantly $(\mathrm{p}<0.05)$ inhibited in diabetic rats when compared with the control group (Figure 4). The substantial low activity of $\Delta 5-3 \beta-\mathrm{HSD}$ was remarkably raised by metaglomide, SBEAB pre and post-treatment in diabetic-induced animals (Figure 4). 
Citation: Ajiboye JA, Akintunde JK, Okewuyi SO, Okafor UE (2017) PUFAs from Stem Bark of Alstonia boonei Synergistically Modulates Diabetic, Hepatic and Androgenic Damage by Low Expression of COX-2 and iNOS in Rats. J Mol Biomark Diagn 8: 334.

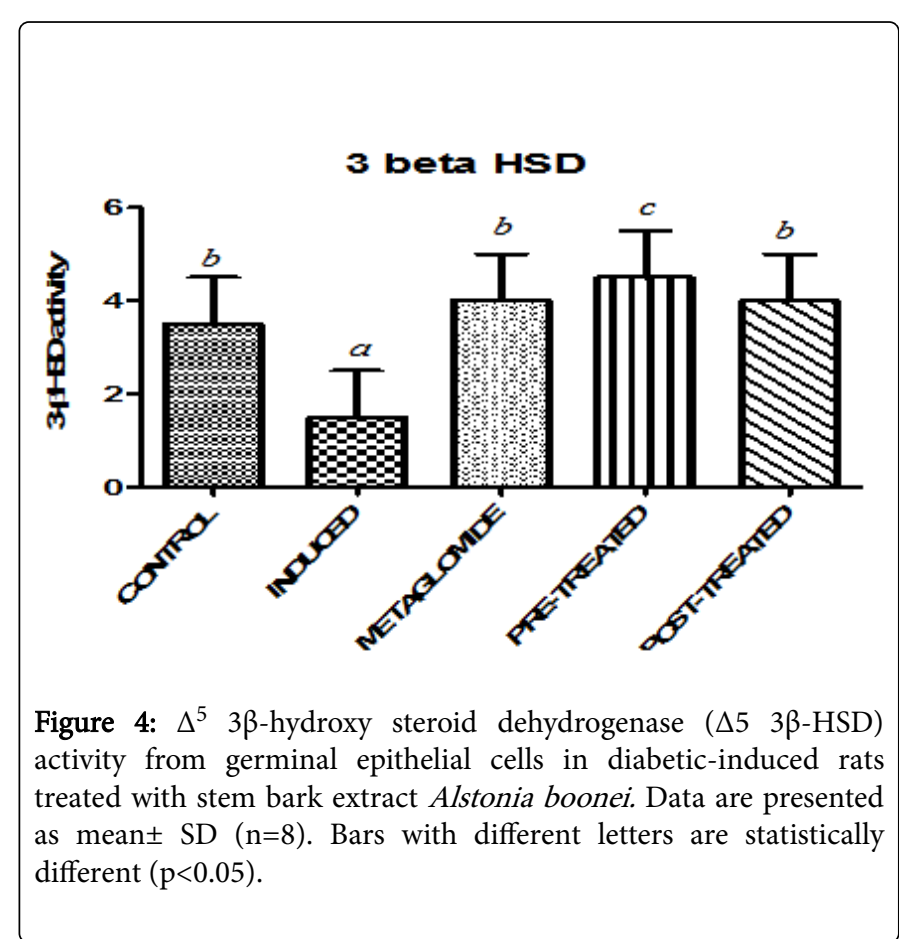

Similarly, the activity of $\Delta 5-17 \beta$-HSD (Figure 5) was significantly ( $\mathrm{p}$ $<0.05)$ depleted in diabetic rats relative to control animals. Whereas the depleted activity of $\Delta 5-17 \beta-H S D$ was significantly $(\mathrm{p}<0.05)$ reversed after metaglomide, pre and post- treatment with SBEAB (Figure 5).

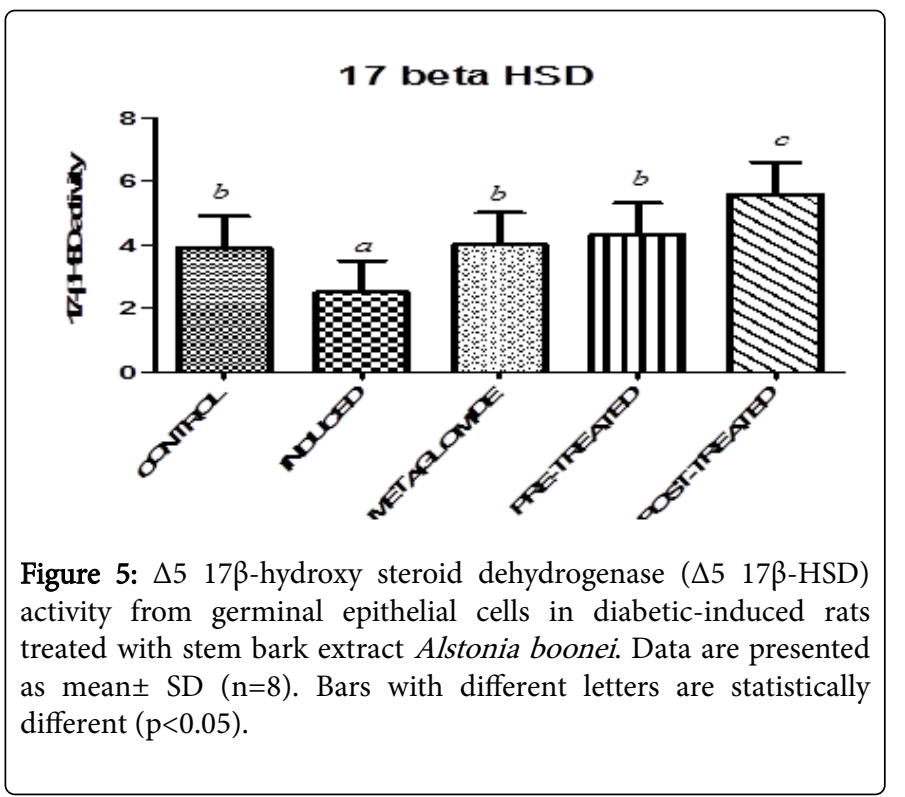

J Mol Biomark Diagn, an open access journal

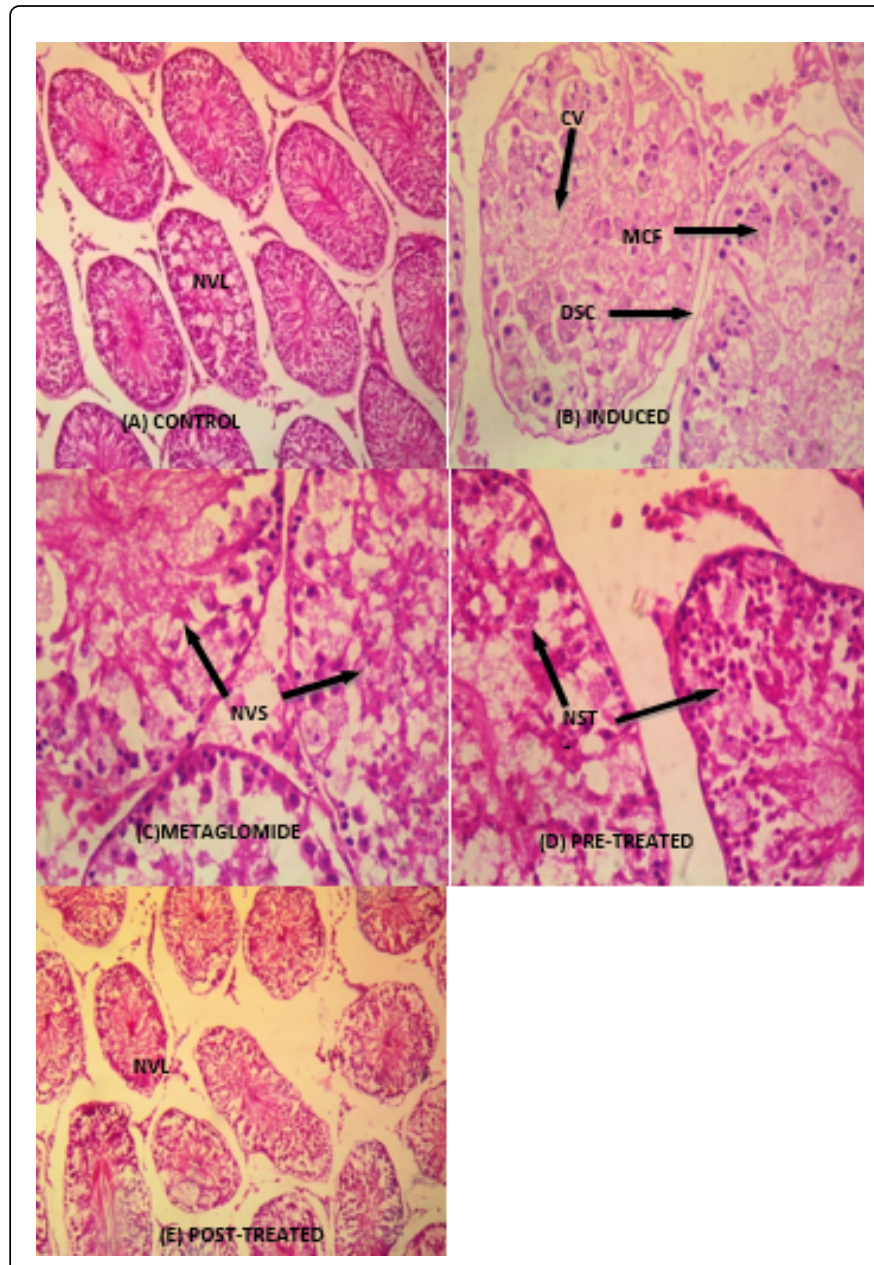

Figure 6: Photomicrographs of eosin and hematoxylin-stained 5- $\mu \mathrm{m}$ thick section (original magnification X 100).

(a) Rat testis showing normal developmental stages of spermatogenesis i.e. No Visible Lesion (NVL).

(b) Diabetic rat testis showed depleted spermatogenic epithelial cells. Also, there were multiple foci of multinucleated cell formation (MCF) as well as cytoplasmic vacuolations (CV), and detachment of spermatogenic cells (DSC) from the basement membrane with numerous seminiferous tubules and fair regular outlines.

(c) Rats treated with metaglomide (anti-diabetic drug) depicted numerous variably-sized seminiferous tubules (NVS) with regular outlines. Most of the seminiferous tubules contain fewer amounts of spermatogenic epithelial cells. Also, the spermatogenic cells show various degrees of degeneration such as marked cytoplasmic vacuolations.

(d) Pre-treated group of animals with the SBEAB demonstrated numerous semiferous tubules (NSTs) with regular outlines. Many of these seminiferous tubules contain moderate amounts of spermatogenic cells while a few contain sparse amounts of spermatogenic cells and only few of the spermatogenic cells were degenerated and vacuolated. 
Citation: Ajiboye JA, Akintunde JK, Okewuyi SO, Okafor UE (2017) PUFAs from Stem Bark of Alstonia boonei Synergistically Modulates Diabetic, Hepatic and Androgenic Damage by Low Expression of COX-2 and iNOS in Rats. J Mol Biomark Diagn 8: 334.

(e) Post-treated group of animals with SBEAB showed numerous variably-sized seminiferous tubules with irregular outlines.

The semineferous tubules contain moderately depleted amounts of spermatogenic cells while the spermatocytes were few and elongated spermatids were frequent.

Histological assessment of testicular samples in addition supported this finding. Hence, testes from diabetic rats showed depleted spermatogenic epithelial cells with cytoplasmic vacuolations and detachment of spermatogenic cells from the basement membrane (Figure 6B) when compared with the control liver (Figure 6A). For metaglomide, SBEAB pre and post-treated rats, the viability of the spermatogenic cells was reasonably conserved (Figures 6C-6E). Thus, the preservative effect of SBEAB pre and post-treatment on testicular damage via androgenic/steroidogenic pathway was more efficacious in diabetic rats when compared to metaglomide administration.

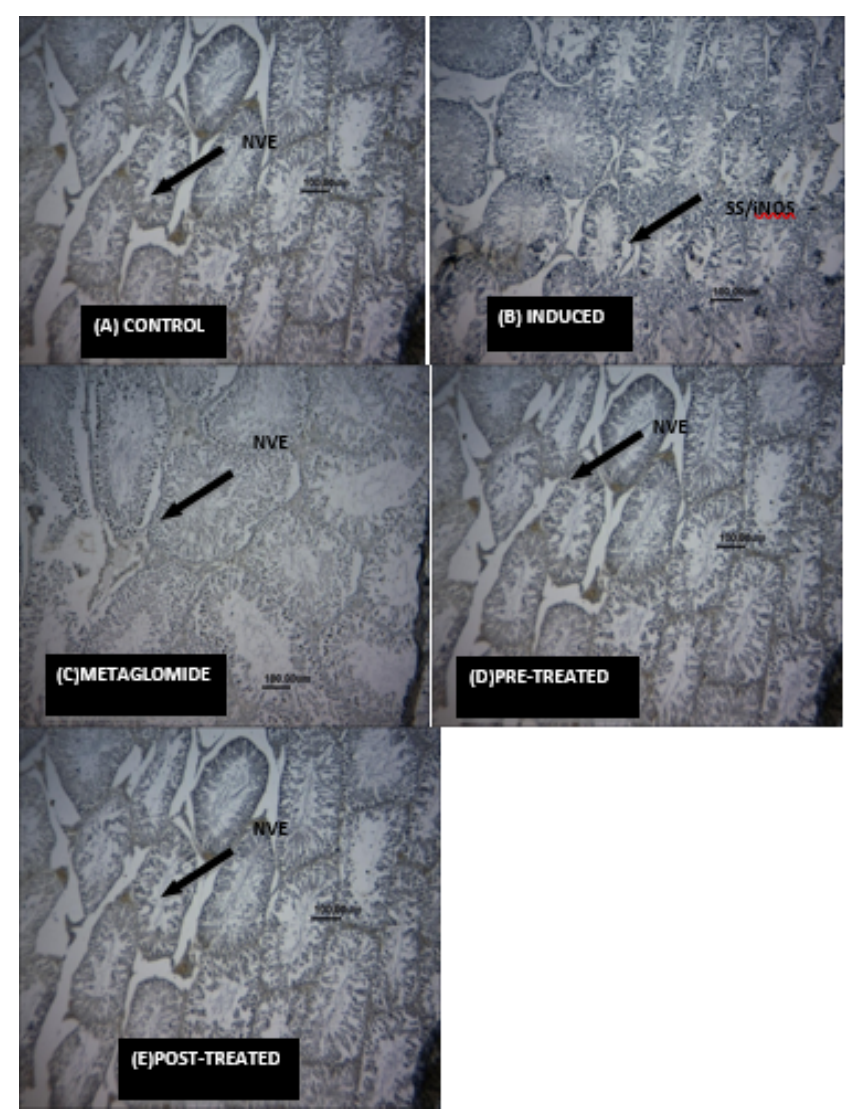

Figure 7: Effect of Alstonia boonei on immunoreactions of inducible nitric oxide synthase (iNOS) expression in diabetic induced rats.

(a) No visible expression (NVE) of iNOS i.e. there were intact and normal architectural structures of the membrane and the spermatids were not affected.

(b) Scattered or eroded spermatids (SS) with broken membrane architectures in diabetic induced rats were antecedent by the expression of iNOS.

(c) There was little expression of iNOS which resulted into mild distortion in the lumen of seminiferous tubules but with intact membrane architectures. (d) No visible expression of iNOS i.e. there were intact and normal architectural structures of the membrane and the spermatids were not affected.

(e) Also, this group showed no visible expression of iNOS. There were intact and normal architectural structures of the membrane and the spermatids were not affected.

The protein expression of iNOS and COX-2 were evaluated in testes of diabetic rats by immunohistochemistry. As shown in Fig. $7 \mathrm{~B}$ and $8 \mathrm{~B}$ respectively, both proteins were highly expressed in diabetic rats when compared to the control. However, metaglomide, SBEAB pre and posttreatment decreased the expression of testicular COX-2 and iNOS proteins in diabetic induced rats. The inhibition of COX-2 and iNOS expression in testes of diabetic rats by SBEAB pre and post-treatment were better than the reference anti diabetic drug-metaglomide (Figure 7 and Table 3).

\begin{tabular}{|l|l|l|}
\hline Treatment & iNOS & COX-2 \\
\hline Control & 0 & 0 \\
\hline Induced & 2 & 2 \\
\hline Metaglomide & 1 & 1 \\
\hline Pre-treatment & 0 & 0 \\
\hline Post-treatment & 0 & 0 \\
\hline $\begin{array}{l}\text { iNOS, inducible nitric oxide synthase; COX-2, cyclooxygenase-2. } \\
\text { Key to scores: } 0=\text { No testicular cancer formation, 1=mild testicular cancer } \\
\text { formation, 2= severe testicular cancer formation. Pre and post-treatment are } \\
\text { more efficacious in preventing testicular cancer in diabetic rats than METAG- } \\
\text { treatment (pre=post >METG). }\end{array}$ & \\
\hline
\end{tabular}

Table 3: Scoring of differential protective effect of SBEAB and metaglomide on iNOS and COX-2 expression in testes of diabetic induced rats.

(a) No visible expression of COX-2 (NVEC) i.e. there was intact and normal architectural structures of the membrane and the spermatids were not affected.

(b) Scattered or eroded spermatids with broken membrane architectures in diabetic induced rats were antecedent by the expression of COX-2 (EC).

(c) There was little expression of COX-2 (LEC) which resulted into mild distortion in the lumen of seminiferous tubules but with intact membrane architectures.

(d) No visible expression of COX-2 (NVEC) i.e. there were intact and normal architectural structures of the membrane and the spermatids were not affected.

(e) Also, this group showed no visible expression of COX-2 (NVEC). There were intact and normal architectural structures of the membrane and the spermatids were not affected (Figure 8). 
Citation: Ajiboye JA, Akintunde JK, Okewuyi SO, Okafor UE (2017) PUFAs from Stem Bark of Alstonia boonei Synergistically Modulates Diabetic, Hepatic and Androgenic Damage by Low Expression of COX-2 and iNOS in Rats. J Mol Biomark Diagn 8: 334.

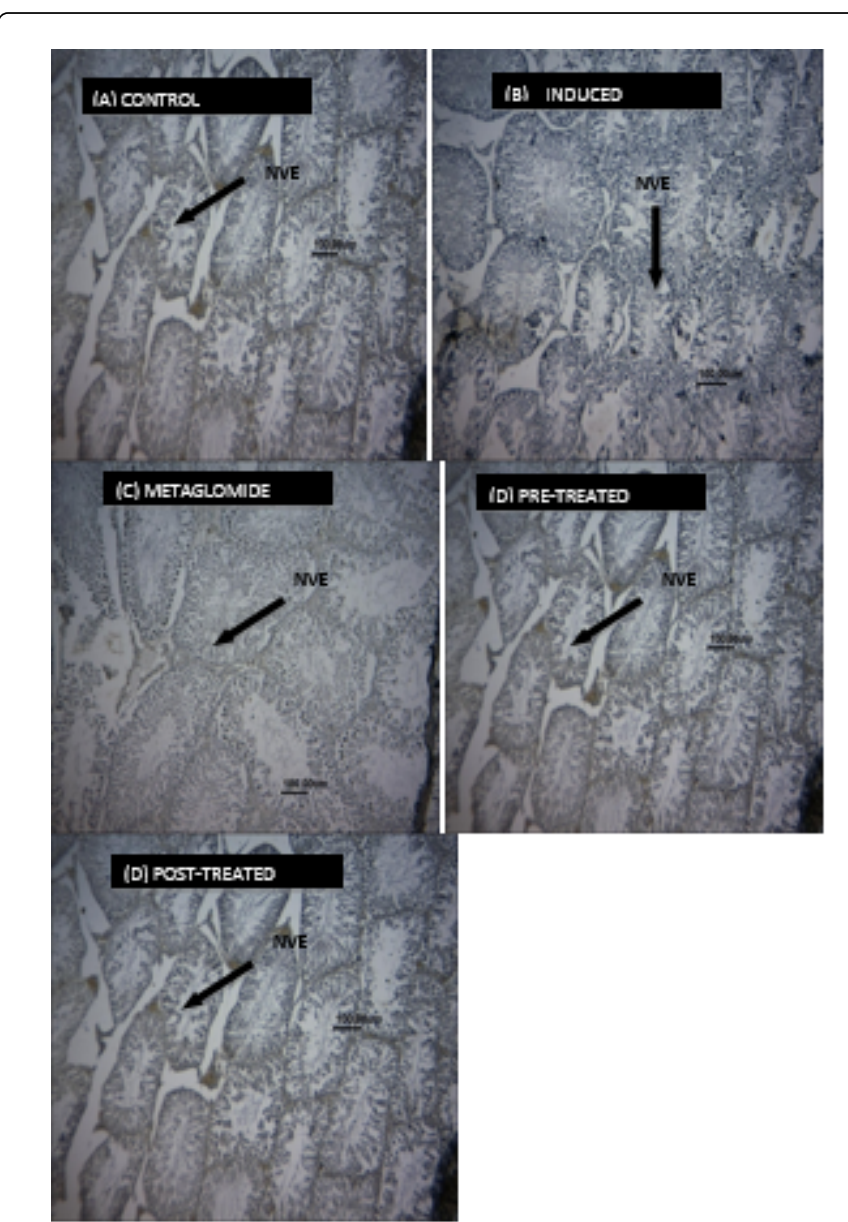

Figure 8: Effect of Alstonia boonei on immunoreactions of cyclooxygenase-2 (COX-2) expression in diabetic induced rats.

\section{Discussion}

The present investigation evaluates the combination effects of essential PUFAs from stem bark Alstonia boonei (SBAB) on hepatic and androgenic enzymes in diabetic induced rats. The GC-MS characterization of SBEAB showed four predominant PUFAs namely; 1,2-epoxycyclooctane, trans-2-nonenal, 1-(2-hydroxyl-1-nitroethyl) cyclohexanol and Spiro [1,3-dioxolane-2,2'-6 (6,7] diazobicyclo [3.2.2 non-6-ene. These have been reported as anti-microbial agent [22], antioxidant and anti-inflammatory mediator [18], anticancer agent, and strong inhibitor of cyclooxygenase-2 (COX-2) [23], while all other compounds were recognized and acted as prophylactics of reacting oxygen species (ROS) [20]. This is in support of previous studies which reported phytochemicals as chemoprevention of diverse diseases and ailments [13]. Recent experimental studies have established the antioxidant and anti-diabetic properties of stem bark Alstonia boonei (SBAB) in experimental animal [26,32] and Escherichia coli [22] models. However, the underlying biochemical and especially molecular mechanisms of hepato- and testo-protection by SBEAB remain to be elucidated. In the present study, we report that stem bark Alstonia boonei and anti-diabetic drug (METAG) inhibit the activities of ALT, AST and MDA contents in rat liver of diabetic rats. The observed reduction in the activities of liver enzymes and lipid peroxidation by
SBEAB in the present study is in agreement with previous observations on the hepatoprotective potential of several natural compounds on a number of hepatotoxic agents $[18,23]$. Similarly, as observed, there was a significant rise in hepatic and testicular MDA contents in diabetic induced rat. This result is in agreement with previous investigations where animals suffering from insulin dependent diabetics (type 1) showed increased lipid peroxidation [21,33]. It was also reported that diabetic patients are more susceptible to membrane damage [32,34]. However, mixture of PUFAs from stem bark Alstonia boonei and antidiabetic drug (METAG) caused a significant reduction in MDA content of diabetic-induced rats. This is in agreement with Harlev et al. [35], where they reported little or no cell membrane lesions in group of diabetic animals treated with natural polyphenols. Hence, we report that people with degenerative diseases especially type 1 diabetes are prone to have hepatic necrosis and reproductive disorders. Also, antioxidant enzyme- catalase (CAT) was significantly increased in the testes of diabetic rats. Both pre and post-treatment with the extract and METAG caused a significant depletion in diabetic-induced rats. Posttreatment is most efficacious in inhibiting CAT activity in type 1 diabetic rat; followed by pre- and METAG-treatment respectively. Reduction on enzymatic antioxidant- CAT was complementary with the results of previous studies $[32,36]$. Also, protective effects of SBEAB on pre and post- treated group were due to free radical scavenging activity. The effect was connected to the phenolic compounds from stem bark Alstonia boonei. This was in agreement with the prior records which indicated polyphenols as scavengers of free radicals [14].

Histopathologically, livers from diabetic rats showed hepatocyte necrosis towards the centrilobular region. This discovery is line with recent development which reported that necrotic damage of the hepatic cells was responsible for the pathogenesis of the liver or its failure [37-40]. Also, another work reported that considerable damage to the hepatocytes was more pronounced in diabetic patients than physiological individuals [41]. This also suggests that the liver functions had been compromised. The group of animal pre and post treated with SBEAB showed moderately preserved hepatocytes. This may be attributed to the presence of essential PUFAs which act as promoter of liver functionality [41]. Totally, anti-diabetic drug (METAG) is most efficacious in potentiating hepatocytes function in diabetic rat followed by post- and pre-treatment respectively. This observation may be linked to the fact that the drug is most systemic to the survival of the liver cells.

Furthermore, our present study showed marked decrease in the activities of steroidogenic enzymes- $\Delta 5 \quad 3 \beta$-hydroxy steroid dehydrogenase $\left(\begin{array}{ll}\Delta 5 & 3 \beta \text {-HSD }\end{array}\right)$ and $\Delta 5 \quad 17 \beta$-hydroxy steroid dehydrogenase $(\Delta 5$ 17 $\beta$-HSD $)$ in diabetic rats. These enzymatic activities advocate possible biochemical mechanisms of toxicity in diabetic men coupled with spermatogenic disorders. This observation was similar to previous study which reported that diabetic men have low levels of testosterone, which is a marker of spermatogenesis [42]. Also, further studies had reported diminution on both $\Delta 53 \beta-\mathrm{HSD}$ and $\Delta 517 \beta$-HSD activities among males distressed with reproductive dysfunctions $[43,44]$. However, pre, post and METAG treatments prevented the reduction of androgenic enzymes activities in diabetic rats. Pre and post treatment with SBEAB was more efficacious than anti-diabetic drug (METAG). The observed elevation could be attributed to synergistic, additive, mutual or joint interactions of the several phenolic compounds. Hence, the increased activity caused by the SBEAB substantiates the link between diabetes and male infertility. 
Moreover, as portrayed from the study, diabetic animal had depleted spermatogenic epithelial cells and cytoplasmic vacuolations with detachment of spermatogenic cells from the basement membrane. These abnormalities were related to the necrospermia and astenospermia [44,45]. This finding is line with recent study which reported that the necrosis of spermatogenic epithelium cells was connected to the low sperm count, reduced sperm motility and depleted daily sperm production [46]. This observation further proposes that the abnormal production of primordial germ cells was as a result of the elevated COX-2 and iNOS expression, markers of proinflammation and testicular cancer [13]. The group of animals pre and post treated with SBEAB showed that the possibility of the spermatogenic cells was realistically conserved. Generally, the differential protection (pre and post) of SBEAB is more efficacious in abrogating testicular damage in diabetic rat than anti-diabetic drug (METAG). This is not unconnected to the presence of essential fatty acids in stem bark of Alstonia boonei.

COX-2 and iNOS are well known pro-inflammatory genes and their expressions have been shown to be regulated by transcription factors $[13,47]$. Recently, attention was focused on molecules mediating inflammation and cancer [48]. This is because there is link between inflammation and cancer $[46,47]$. The inhibition of intracellular inflammatory response is now a sure recipe for developing molecular target-based chemopreventive agents [13]. The present study revealed that pre and post treatment with Alstonia boonei abolished the expression of these genes (COX-2 and iNOS) in testicular of diabeticinduced rat. Taken together, pre and post-treatment are more efficacious in preventing pro-inflammatory response and testicular cancer in diabetic rats than METAG-administration. The results therefore suggest that SBEAB may be significant not only in assuaging testes inflammation but also for the prevention of testicular or prostate cancer. It's also suggests that physiological task of SBEAB was directly connected with its ability to inhibit the activation of transcription factors such as NF- $\kappa \mathrm{B}, \mathrm{AP}-1$ and MAPK $[47,48]$ thereby downregulating the expression of COX-2 in rats' testes stimulated with toxicant. This study corroborated the recent finding which reported that cyclooxygenase- 2 is an enzyme engaged in inflammatory processes and a committed step in prostaglandin biosynthesis from arachidonic acid [49]. Further reports also discovered that inappropriate up-regulation of COX-2 was commonly observed in various premalignant and malignant tissues [50]. In addition, over expression of COX-2 was further noted in transgenic mice with tumor [16] and experimentally-induced carcinogenesis [13,51]. However, the repression of COX-2 and iNOS proteins underscores the molecular basis for the testicular cancer protection by SBEAB in diabetic-induced rats.

\section{Conclusion}

Essential fatty acids prevented the leakage of AST and ALT into the blood circulation with corresponding decreased in MDA levels of both liver and testes. The activities of $\Delta 5-17 \beta$-HSD and $\Delta 5-17 \beta-$ HSD were significantly elevated in animal group subjected to SBEAB with corresponding decrease in the activity of CAT. Animals treated with SBEAB showed moderately and pragmatic preserved hepatocytes and normal spermatogenic cells. Anti-diabetic drug (METAG) treatment on hepatic damage was most efficacious in diabetic rats; followed by post and pre-treatment respectively while pre and post treatment were more efficacious on testicular damage than anti-diabetic drug (METAG). Furthermore, pre and post-treatment are more efficacious in preventing pro-inflammatory response and testicular cancer in diabetic rats than METAG-administration. We therefore concluded that the repression of genes encoding COX-2 and iNOS proteins validates the molecular basis of the testes protection by SBEAB and further suggests the links between the hepatocellular damage and male reproductive dysfunctions in diabetic individuals.

\section{References}

1. Mariana M, Lijun M, Barry I F (2012) Genetic and environmental factors associated with type 2 diabetes and diabetic vascular complications. Rev Diabet Stud. Spring 9: 6-22.

2. Giraldi A, Kristensen E (2010) Sexual dysfunction in women with diabetes mellitus. J Sex Res 47: 199-211.

3. Guillaume A, Oluwafemi OO, Stefan SD (2013) Can lifestyle factors of diabetes mellitus patients affect their fertility? Intech 6: 96-116.

4. Tang ZH, Fang Z, Zhou L (2013) Human genetics of diabetic vascular complications. J Genet 92: 677-694.

5. Soon HS (2015) Complication characteristics between young-onset type 2 versus type 1 diabetes in a UK population. BMJ Open Diabetes Res Care 3: e000044.

6. Nolen-Hoeksema S (2014) Abnormal psychology. McGraw-Hill, New York, NY USA.

7. Wylie KR (2015) ABC of sexual health. John Wiley \& Sons, USA.

8. Wentzell E (2013) Aging respectably by rejecting medicalization: Mexican men's reasons for not using erectile dysfunction drugs". Med Anthropol 27: 3-22.

9. Alves MG, Martins AD, Rato L, Moreira PI, Socorro S, et al. (2013) Molecular mechanisms beyond glucose transport in diabetes-related male infertility. Biochim Biophys Acta 1832: 626-635.

10. Slavica T, Mahasin AO (2015) The double trouble of metabolic diseases: the diabetes-cancer link Mol Biol Cell 26: 3129-3139.

11. Kim SO, Kundu JK, ShinYK, Park JH, Cho MH, et al. ( 2005) 6-Gingerol inhibits COX-2 expression by blocking the activation of p38 MAP kinase and NF-kappaB in phorbol ester-stimulated mouse skin. Oncogene 24: 2558-2567.

12. Chung WY, Park JH, Kim MJ, Kim HO, Hwang JK, et al. (2007) Xanthorrhizol inhibits 12-O tetradecanoylphorbol-13-acetate-induced acute inflammation and two-stage mouse skin carcinogenesis by blocking the expression of ornithine decarboxylase, cyclooxygenase- 2 and inducible nitric oxide synthase through mitogen-activated protein kinases and/or the nuclear factor-kappa B. Carcinogenesis 28: 1224-1231.

13. Farombi EO, Shrotriya S, Surh Y (2008) Kolaviron inhibits dimethyl nitrosamine-induced liver injury by suppressing COX-2 and iNOS expression via NF- $\kappa$ B and AP-1. Life Sciences 84: 149-155.

14. Oboh G, Akinyemi AJ, Ademiluyi AO, Adefegha SA (2010a) Inhibitory effects of aqueous extract of two varieties of ginger on some key enzymes linked to type-2 diabetes in vitro. J Food Nutri Res 49: 14-20.

15. Oboh G, Adefegha SA, Rocha JBT (2010b) Fe2+ and sodium nitroprusside-induced oxidative stress in rat's brain (in vitro): Protective Effects of Aqueous Extract of Mentha viridis and Majarona hortensis Leaves. Advances in Food Sciences 32: 11-19.

16. Wang X, Colby JK, Rengel RC, Fischer SM, Clinton SK, et al. (2009) Overexpression of cyclooxygenase-2 (COX-2) in the mouse urinary bladder induces the expression of immune- and cell proliferation-related genes. Mol Carcinogen 48: 1-13.

17. Oboh G, Rocha JB (2007) Antioxidant in foods: a new challenge for food processors. Leading Edge Antioxidants Research, Nova Science Publishers Inc, New York, USA.

18. Ming H, Sha Li, Hor Yue T, Ning W, Sai-Wah T, et al. (2015) Current status of herbal medicines in chronic liver disease therapy: The biological effects, Molecular Targets and Future Prospects; Int J Mol Sci 16: 28705-28745. 
Citation: Ajiboye JA, Akintunde JK, Okewuyi SO, Okafor UE (2017) PUFAs from Stem Bark of Alstonia boonei Synergistically Modulates Diabetic, Hepatic and Androgenic Damage by Low Expression of COX-2 and iNOS in Rats. J Mol Biomark Diagn 8: $334 . \quad$ doi: $10.4172 / 2155-9929.1000334$

Page 9 of 9

19. Nair HB, Sung B, Yadav VR, Kannappan R, Chaturvedi MM, et al. (2010) Delivery of antiinflammatory nutraceuticals by nanoparticles for the prevention and treatment of cancer. Biochem Pharmacol 80: 1833-1843.

20. Chan EWC, Lim Y, Wong S (2009) Effects of different drying methods on the antioxidant properties of leaves and tea of ginger species. Food Chem 113: 166-172.

21. Saba AB, Oyagbemi AA, Azeez OI (2010) Antidiabetic and haematinic effects of Parquetina nigrescens on alloxan induced type-1 diabetes and normocytic normochromic anaemia in Wistar rats. Afr Health Sci 10: 276-282.

22. Fabiyi OA, Atolani O, Olatunji GA (2012) Nematicidal activity of Alstonia boonei and Bridelia ferruginea leaves. Albanian j agric sci 11 : 2218-2020.

23. Onifade OF, Maganda V (2015) In vivo activity of ethanolic extract of Alstonia boonei leaves against Plasmodium berghei in Mice JWHSD 1: 60-68.

24. Milani E, Nikfar S, Khorasani R, Zamani MJ, Abdollahi M (2005) Reduction of diabetes-induced oxidative stress by phosphodiesterase inhibitors in rats. Comparative Biochemistry \& Physiology C 140: 251-255.

25. Akinloye OA, Oshilaja RT, Okelanfa OA, Akinloye DI, Idowu OM (2013) Hypoglyceamic activity of Alstonia boonei stems bark extract in mice. Agric Biol J N Am 4: 1-5.

26. Reitmann S, Frankel S (1957) Colorimetric method for the determination of serum transaminase activity. Am J Clin Pathol 28: 56-68.

27. Ohkawa H, Ohishi N, Yagi K (1979) Assay for lipid peroxides in animal tissues by thiobarbituric acid reaction. Analytical biochemistry 95: 351-358.

28. Clairborne AI (1995) Catalase activity. In: Greewald AR, Handbook of methods for oxygen radical research. Florida, CRC Press, USA.

29. Ulmer VerlagLowry OH, Rosebrough NJ, Farr AL, Randall RJ (1951) Protein measurement with Folin-phenol reagent. J Biol Chem 193: 265275.

30. Zar JH (1984) Biostatistical analysis. Prentice-Hall, International, USA.

31. Barnabé L, Nkono YS, Dongmo S, Dzeufiet D, Paul D, et al. (2014) Antihyperglycemic and antioxydant properties of Alstonia boonei De Wild. (Apocynaceae) Stem Bark Aqueous Extract in DexamethasoneInduced Hyperglycemic Rats Int J Diab Res 3: 27-35.

32. Oršolić N, Sirovina D, Gajski G, Garaj-Vrhovac V, Jazvinšćak Jembrek M, et al. (2013) Assessment of DNA damage and lipid peroxidation in diabetic mice: effects of propolis and epigallocatechin gallate (EGCG) Mutat Res 757: 36-44.

33. Sengupta U, Ukil S, Dimitrova N, Agrawal S (2009) Expression-based network biology identifies alteration in key regulatory pathways of type 2 diabetes and associated risk/complications. PLoS One 4: e8100.

34. Harlev E, Nevo E, Mirsky N, Ofir R (2013) Antidiabetic attributes of desert and steppic plants: a review. Planta Med 79: 425-436.

35. Helmstädter A (2012) Antidiabetic medicinal plants between phytotherapy and lead structure research. Pharm Hist 54: 99-108.

36. Joseph C M, Jeffrey W B, Adara M (2010) Natural anti-inflammatory agents for pain relief. Surg Neurol Int 1: 80 .
37. Farombi EO, Akintunde JK, Nsute N, Adedara IA, Arojojoye O (2011) Municipal landfill leachate induces hepatotoxicity and oxidative stress in rats. J Toxicol Ind Health 28: 532-541.

38. Akintunde JK, Oboh G (2015) Depletion of cellular adenosine triphosphate and hepatocellular damage in rat after subchronic exposure to leachate from anthropogenic recycling site. Hum Exp Toxicol 31: 1-13.

39. Akintunde JK, Bolarin OE (2015) Research on garlic capsule and selenium-vitamin A, vitamin B, vitamin C applied in therapy of acute hepatocellular damage in a rat mode. J Acute Dis 4: 298-304.

40. Ajiboye JA, Akintunde JK, Oladejo OS, Sabiu SA (2015) Chemoprevention of silymarin and vitamin $\mathrm{C}$ on isoniazid-induced hepatotoxicity in experimental rat model. J Toxins 2: 3 .

41. Nada Oršolić DS, Marijana ZK, Gordana L, Gordana G (2012) Effect of Croatian propolis on diabetic nephropathy and liver toxicity in mice. BMC Complement Altern Med 12: 117.

42. Dandona P, Dhindsa S, Chandel A, Topiwala S (2009) Low testosterone in men with type 2 diabetes, a growing public health concern. Diabetes Voice 54: 27-29.

43. Carlo F, Giacomo S, Luca DT, Lisa P, Antonella DM, et al. (2011) Bone mineral density and testicular failure: evidence for a role of vitamin D 25 hydroxylase in human testis. The Journal of Clinical Endocrinology and Metabolism 96: E646-652.

44. Akintunde JK, Oboh G (2013) Exposure to leachate from municipal battery recycling site: implication as key inhibitor of steroidogenic enzymes and risk factor of prostate damage in rats. Env. Health 28: 107-115.

45. Yu H, Diao H, Wang C, Lin Y, Yu F, et al. (2015) Acetylproteomic analysis reveals functional implications of lysine acetylation in human spermatozoa (sperm). Mol Cell Proteomics 14: 1009-1023.

46. Akintunde JK, Oboh G, Akindahunsi AA (2015) Sub-chronic exposure to EOMABRS leachate induces germinal epithelial cell lesions, sperm abnormalities and oxidative damage in rats. Asian Pacific Journal of Reproduction.4: 288-297.

47. Shiby P, Agnes MR, Hong JL, Yan J, Bandaru SR, et al. (2009) Antiinflammatory action of pterostilbene is mediated through the p38 MAPK pathway in colon cancer cells. Cancer Prev Res (Phila) 2: 650-657.

48. Khuda-Bukhsh AR, Das S, Saha SK (2014) Molecular approaches toward targeted cancer prevention with some food plants and their products: inflammatory and other signal pathways. Nutr Cancer 66: 194-205.

49. William LS, Yoshihiro U, Per-Johan J (2011) Enzymes of the cyclooxygenase pathways of prostanoid biosynthesis. Chem Rev 111: 5821-5865.

50. Shrimali D, Shanmugam MK, Kumar AP, Zhang J, Tan BK, et al. (2013) Targeted abrogation of diverse signal transduction cascades by emodin for the treatment of inflammatory disorders and cancer. Cancer Lett 341 : 139-149.

51. Leung WK, Wu KC, Wong CY, Cheng AS, Ching AK, et al. (2008) Transgenic cyclooxygenase-2 expression and high salt enhanced susceptibility to chemical-induced gastric cancer development in mice. Carcinogenesis 29: 1648-1654. 